\title{
Histopathology and elastography discordance in evaluation of breast lesions with acoustic radiation force impulse elastography
}

\author{
Nurşen Toprak ${ }^{A, B, D, E}$, Adem Yokus ${ }^{\mathrm{E}, \mathrm{F}, \mathrm{G}}$, Mahir Gündüz ${ }^{\mathrm{C}, \mathrm{D}, \mathrm{F}}$, Huseyın Akdenız ${ }^{\mathrm{A}, \mathrm{B}, \mathrm{C}}$ \\ Van Yyu Dursun Odabas Medical Centre, Tuşba/Van, Turkey
}

\section{Abstract}

Purpose: It is known that, besides its benefits, ultrasound (US) elastography may show discordance findings, leading to biopsy, so this technique has some limitations. The purpose of the present study was to compare histopathological results and shear wave velocity (SWV) values in patients, to reveal discordance findings, and to investigate its statistical significance in making the decision for biopsy with SWV values.

Material and methods: A total of 190 patients presenting with breast lesions were included in the study. The mean age of the patients was $39.87 \pm 13.56$ years. All morphological features of lesions were evaluated by B-mode US. The mean SWV values were measured using the region of interest (ROI) through all lesions with ARFI elastography. An ultrasound-guided Tru-Cut needle biopsy was performed, and histopathologic data were obtained.

Results: The SWV values of false positive benign lesions, such as: granulomatous mastitis, sclerosing adenosis, chronic inflammation, fat necrosis, fibrotic breast tissue, and scar tissue, were as high as the SWV values of malignant lesions. Sensitivity was found as $91.6 \%$ and specificity as $40.9 \%$ for SWV values in ARFI US.

Conclusions: Our results showed that breast lesions showed false positivity (59.1\%) and false negativity (8.3\%) in ARFI US. Elastography is useful and sensitive in the evaluation of breast lesions, but some benign lesions may mimic malignant lesions; thus, this information should not be underestimated in biopsy decision-making for elastography users.

Key words: breast lesion, ARFI elastography, discordant findings.

\section{Introduction}

Breast cancer is among the leading causes of death among women in developing countries [1]. Early detection of a cancerous lesion significantly affects the prognosis of the patient. Therefore, many devices are used in radiology practice for early diagnosis. Mammography is the most important technique. In addition, magnetic resonance imaging (MRI) and ultrasonography (US) are adjutant modalities for mammography [2].

Breast US is an important imaging tool for identification and characterisation of breast lesions [3]. High-frequency and the high-resolution of US is helpful in the evaluation of the breast, especially in young patients and women with a dense breast on mammography. Compared with mammography, breast MRI, and biopsy, US is advantageous because it is an inexpensive, radiation free, reproducible, and non-invasive method [2]. However, despite its high sensitivity in the breast, US shows a low specificity. This causes numerous false positive findings. In addition, US depends on the operator $[4,5]$. High incidence and slow progression of breast cancer before the diagnosis have led to research on new diagnostic techniques $[4,5]$. Therefore, several complementary techniques have been developed to increase the specificity of breast US [6]. US elastography defined in the breast imaging-reporting and data system (BI-RADS) category is among these techniques. US elastography is a new method, which measures

Correspondence address:

Dr. Nurşen Toprak, Van Yyu Dursun Odabas Medical Centre, Tuşba/Van, Turkey, e-mail: nursentoprak31@gmail.com

Authors' contribution:

A Study design · B Data collection · C Statistical analysis · D Data interpretation - E Manuscript preparation · F Literature search · G Funds collection 
the degree of hardness of breast lesions. US elastography can provide quantitative information that is helpful to identify malignant and benign lesions [2]. More recently, systems equipped with various methods that apply strain have become available. They include systems with strain elastography (SE), which requires manual compression vibration, and systems equipped shear wave elastography (SWE) technology that supplies vibrational energy by means of ultrasound. These methods share the concept of bringing qualitative diagnostic capability, i.e. imaging and numerical expression of the stiffness of a target, into the field of ultrasonography, which is primarily concerned with morphological diagnosis [7]. There are various methods and terms related to diagnostic assessment, such as elasticity scores (Tsukuba score, strain pattern), $\mathrm{E} / \mathrm{B}$ ratio (width ratio, length ratio), strain ratio, fat-lesion ratio (FLR), and shear wave measurements $(\mathrm{kPa}$, and $\mathrm{m} / \mathrm{s})$, which often lead to confusion when initially using elastography [7].

In this study, we used shear wave velocity (SWV) measurement values showing the speed of the sound wave obtained by acoustic radiation force impulse (ARFI) technology in the tissue. There are many studies on this issue that have reported different SWV measurement values for malignant and benign lesions $[4,8]$. Elasticity features may overlap in benign and malignant lesions depending on histopathological characteristics in breast tumours. It is known that, besides its benefits, ARFI US examination may show false positivity, leading to biopsy [9].

The objective of this study was to compare histopathological results and SWV values on ARFI elastography in patients who underwent breast biopsy in our clinic, to reveal benign lesions showing false positivity and malignant lesions showing false negativity, and to investigate its statistical significance in making the decision for biopsy with SWV values.

\section{Material and methods}

The study was retrospectively conducted in the Breast Radiology Unit of Van YYU Medical Faculty, Department of Radiology between August 2017 and April 2018. The study was reviewed and approved by the local Ethics Committee. Informed consent was obtained from all patients before histopathological sampling.

A total of 190 patients aged between 18 and 78 years (mean age of the patients was $39.87 \pm 13.56$ years) were included in the study. All patients presented with symptoms such as palpable breast mass (60\%) or breast pain (40\%). 190 breast lesions of 190 women, which had been performed for ultrasound-guided core needle biopsy, were included in this study. A 14G Tru-Cut biopsy needle was used for biopsy. After the biopsy, malignant lesions were surgically excised.

B-mode US, ARFI sonoelastography, and biopsy were made by a radiologist with two years' experience in the breast. One other radiologist with two years' experience in the breast was blinded to the histopathology results and assessed the B-mode US images and SWV values of each lesion from the PACS. All lesions' B-mode US features were retrospectively analysed and classified according to BI-RADS for US recommended by the American College of Radiology (ACR) [9]. US features were classified as margin (circumscribed, non-circumscribed), shape (irregular, oval-round), posterior acoustic features (shadow, enhancement, mixed, nonenhancement), and echo pattern (markedly hypoechoic, hypoechoic, hyperechoic, isoechoic, complex). In addition, the presence of calcification was recorded. Lesions were categorised as BI-RADS 3-5. According to ACR-BI-RADS Atlas 2013, while the BI-RADS category 3 should be followed, the diagnosis of tissue was made because of the concern of the clinician and the patient. All of the scar tissue and fat necrosis lesions in our patient group were at the irregular border, and they could not be compared using old films, so histopathology was performed in this patient group to exclude local recurrence. Cystic lesions for which histopathological outcomes could not be obtained were excluded.

The mean SWV values were measured using the region of interest (ROI) through all lesions with ARFI elastography. ROI was placed into the hardest and softest locations, and the measures were averaged. The histopathological outcomes were considered as the gold standard. The mean SWV values were compared with histopathological results and US BI-RADS categorisation. The lesions were classified as less than $2 \mathrm{~cm}$, and greater than or equal to $2 \mathrm{~cm}$.

The classification criterion used in ARFI measurement depends on SWV. The mean SWV values vary between 4.49 and $8.22 \pm 1.27 \mathrm{~m} / \mathrm{s}$ in malignant and $2.25 \pm 0.59 \mathrm{~m} / \mathrm{s}$ and $3.25 \pm 2.03 \mathrm{~m} / \mathrm{s}$ in benign lesions [4,8]. Individual values differ among different studies, but these differences are possibly associated with the number of cases, the size, and the histological type of lesions. A cut-off of $3.065 \mathrm{~m} / \mathrm{s}$ was recommended to provide sufficient sensitivity and specificity [4]. Considering the previous studies, we accepted $3 \mathrm{~m} / \mathrm{s}$ as the cut-off for ARFI SWV to distinguish malignant and benign lesions. The lesions with an SWV $<3 \mathrm{~m} / \mathrm{s}$ were considered as benign, and those with an $\mathrm{SWV} \geq 3 \mathrm{~m} / \mathrm{s}$ were accepted as malignant. The lesions showing an SWV incompatible with histopathological outcomes were determined, and accordingly sensitivity, specificity, positive predictive value, and negative predictive value were calculated.

B-mode Breast US was obtained with an ACUSON S 2000 US system (Siemens Medical Solutions) equipped with a bandwidth of $14 \mathrm{MHz}$ and with a wide-format 50-mm linear array transducer. The quantitative implementation of ARFI technology (Virtual Touch Quantification - VTQ) was obtained using a linear-array transducer (9L4; Siemens Medical Solutions) with a bandwidth of $9 \mathrm{MHz}$. 


\section{Statistical analysis}

Sensitivity, specificity, and accuracy of SWV and BI-RADS categorisation were calculated using SPSS v16 software. Independent sample $t$-test and $\chi^{2}$ tests were used for descriptive statistics. Chi-square test was used for BI-RADS categorisation and histopathology comparison. Values of $p<0.05$ were considered statistically significant.

\section{Results}

Of all lesions, 36 (18.9\%) were malignant and 154 (81.05\%) were benign. Patients were aged between 18 and 78 years. The mean age was $36.8 \pm 11.7$ years in patients with benign lesions. The mean size of benign lesions was 24.15 $\pm 14.04 \mathrm{~mm}$. Subtypes, morphological features, and SWV values of the benign lesions are shown in Table 1.

Table 1. Morphological characteristics and mean shear wave velocity (SWV) values of benign lesions

\begin{tabular}{|c|c|c|c|c|c|c|c|c|}
\hline \multirow[t]{2}{*}{ US features } & \multicolumn{8}{|c|}{ Benign histopathology (HPE) } \\
\hline & $\begin{array}{c}\text { FA } \\
n(\%)\end{array}$ & $\begin{array}{c}\text { Granulomatous } \\
\text { mastitis } \\
n(\%)\end{array}$ & $\begin{array}{c}\text { Sclerosing } \\
\text { adenosis } \\
n(\%)\end{array}$ & $\begin{array}{c}\text { Non-specific } \\
\text { inflammation-mastitis } \\
n(\%)\end{array}$ & $\begin{array}{c}\text { Fat } \\
\text { necrosis } \\
n(\%)\end{array}$ & $\begin{array}{c}\text { Fibrotic } \\
\text { breast tissue } \\
n(\%)\end{array}$ & $\begin{array}{l}\text { Scar } \\
\text { tissue } \\
n(\%)\end{array}$ & $\begin{array}{l}\text { Other } \\
n(\%)\end{array}$ \\
\hline \multicolumn{9}{|l|}{ Echo pattern } \\
\hline Markedly hypoechoic & $0(0.0)$ & $0(0.0)$ & $0(0.0)$ & $0(0.0)$ & $0(0.0)$ & $0(0.0)$ & $0(0.0)$ & $1(6.2)$ \\
\hline Hypoechoic & $55(90.2)$ & $1(5.3)$ & $13(100)$ & $4(19.0)$ & $1(12.5)$ & $8(88.9)$ & $1(14.3)$ & $7(43.8)$ \\
\hline Isoechoic & $0(0.0)$ & $0(0.0)$ & $0(0.0)$ & $0(0.0)$ & $1(12.5)$ & $0(0.0)$ & $1(14.3)$ & $0(0.0)$ \\
\hline Hyperechoic & $0(0.0)$ & $0(0.0)$ & $0(0.0)$ & $0(0.0)$ & $2(25.0)$ & $0(0.0)$ & $1(14.3)$ & $0(0.0)$ \\
\hline Complex & $6(9.8)$ & $18(94.7)$ & $0(0.0)$ & $17(81.0)$ & $4(50.0)$ & $1(11.1)$ & $4(57.1)$ & $8(50)$ \\
\hline \multicolumn{9}{|l|}{$p=0.00$} \\
\hline \multicolumn{9}{|l|}{ Orientation } \\
\hline Parallel & $41(67.2)$ & $0(0.0)$ & $3(23.1)$ & $3(14.3)$ & $0(0.0)$ & $3(33.3)$ & $1(14.3)$ & $5(31.2)$ \\
\hline Not parallel & $20(32.8)$ & $19(100.0)$ & $10(76.9)$ & $18(85.7)$ & $8(100)$ & $6(66.7)$ & $6(85.7)$ & $11(68.8)$ \\
\hline \multicolumn{9}{|l|}{$p=0.00$} \\
\hline \multicolumn{9}{|l|}{ Shape } \\
\hline Irregular & $15(24.6)$ & $18(94.7 \%)$ & $6(46.2)$ & $18(85.7)$ & $8(100.0)$ & $8(88.9)$ & $7(100)$ & $8(50)$ \\
\hline Oval/round & $46(75.4)$ & $1(5.3)$ & $7(53.8)$ & $3(14.3)$ & $0(0.0)$ & $1(11.1)$ & $0(0.0)$ & $8(50)$ \\
\hline \multicolumn{9}{|l|}{$p=0.00$} \\
\hline \multicolumn{9}{|l|}{ Margin } \\
\hline Circumscribed & $50(82.0)$ & $1(5.3)$ & $6(46.2)$ & $2(9.5)$ & $0(0.0)$ & $1(11.1)$ & $0(0.0)$ & $9(56.2)$ \\
\hline Non-circumscribed & $11(18.0)$ & $18(94.7)$ & $7(53.8)$ & $19(90.5)$ & $8(100)$ & $8(88.9)$ & $7(100.0)$ & $7(43.8)$ \\
\hline \multicolumn{9}{|l|}{$p=0.013$} \\
\hline \multicolumn{9}{|l|}{ Calcification } \\
\hline Present & $2(3.3)$ & $0(0.0)$ & $0(0.0)$ & $3(14.3)$ & $0(0.0)$ & $0(0.0)$ & $0(0.0)$ & $0(0.0)$ \\
\hline Absent & $59(96.7)$ & $19(100.0)$ & $13(100.0)$ & $18(85.7)$ & $8(100)$ & $9(100.0)$ & $7(100.0)$ & $16(100.0)$ \\
\hline \multicolumn{9}{|l|}{$p=0.014$} \\
\hline \multicolumn{9}{|l|}{ Posterior features } \\
\hline Shadowing & $1(1.6)$ & $0(0.0)$ & $1(7.7)$ & $0(0.0)$ & $5(62.5) 1$ & $3(33.3)$ & $1(14.3)$ & $0(0.0)$ \\
\hline Enhancement & $39(63.9)$ & $2(10.5)$ & $1(7.7)$ & $7(33.3)$ & $(12.5) 1$ & $0(0.0)$ & $1(14.3)$ & $6(37.5)$ \\
\hline Mixt & $15(24.6)$ & $12(63.2)$ & $6(46.2)$ & $7(33.3)$ & $(12.5) 1$ & $4(44.4)$ & $3(42.9)$ & $5(31.2)$ \\
\hline Nonenhancement & $6(9.8)$ & $5(26.3)$ & $5(38.5)$ & $7(33.3)$ & $(12.5)$ & $2(22.2)$ & $2(28.6)$ & $5(31.2)$ \\
\hline \multicolumn{9}{|l|}{$p=0.00$} \\
\hline \multicolumn{9}{|l|}{ Size } \\
\hline$<2 \mathrm{~cm}$ & $24(39.3)$ & $7(36.8)$ & $10(76.9)$ & $11(52.4)$ & $6(75.0)$ & $9(100.0)$ & $2(28.6)$ & $11(68.8)$ \\
\hline$\geq 2 \mathrm{~cm}$ & $37(60.7)$ & $12(63.2)$ & $3(23.1)$ & $10(47.6)$ & $2(25.0)$ & $0(0.0)$ & $5(71.4)$ & $5(31.2)$ \\
\hline Mean SWV $(\mathrm{m} / \mathrm{s}) \pm S D$ & $3.7 \pm 1.13$ & $4 \pm 1.21$ & $3.9 \pm 1.3$ & $5.2 \pm 2.08$ & $5.4 \pm 2.06$ & $3.6 \pm 0.91$ & $4.9 \pm 1.40$ & $2.75 \pm 1.22$ \\
\hline Total & $61(40.4)$ & $19(12.3)$ & $13(8.4)$ & $21(13.6)$ & $8(5.2)$ & $9(5.8)$ & $7(4.5)$ & $16(10.4)$ \\
\hline
\end{tabular}

SD - standard deviation, $p<0.05$, FA - fibroadenoma 
Table 2. Morphological characteristics and mean shear wave velocity (SWV) values of malignant lesions

\begin{tabular}{|c|c|c|c|c|c|}
\hline \multirow[t]{2}{*}{ US features } & \multicolumn{5}{|c|}{ Malignant histopathology } \\
\hline & $\begin{array}{c}\text { IDC } \\
n(\%)\end{array}$ & $\begin{array}{c}\text { Mucinous carcinoma } \\
n(\%)\end{array}$ & $\begin{array}{c}\text { Adenocarcinoma } \\
n(\%)\end{array}$ & $\begin{array}{c}\text { Cribriform cancer } \\
n(\%)\end{array}$ & $\begin{array}{l}\text { DCIS } \\
n(\%)\end{array}$ \\
\hline \multicolumn{6}{|l|}{ Echo pattern } \\
\hline Markedly hypoechoic & $9(32.1)$ & $0(0.0)$ & $0(0.0)$ & $0(0.0)$ & $0(0.0)$ \\
\hline Hypoechoic & $18(64.3)$ & $1(50)$ & $4(100)$ & $1(100.0)$ & $1(100)$ \\
\hline Isoechoic & $0(0.0)$ & $0(0.0)$ & $0(0.0)$ & $0(0.0)$ & $0(0.0)$ \\
\hline Hyperechoic & $0(0.0)$ & $0(0.0)$ & $0(0.0)$ & $0(0.0)$ & $0(0.0)$ \\
\hline Complex & $1(3.6)$ & $1(50)$ & $0(0.0)$ & $0(0.0)$ & $0(0.0)$ \\
\hline \multicolumn{6}{|l|}{$p=0.00$} \\
\hline \multicolumn{6}{|l|}{ Orientation } \\
\hline Parallel & $1(3.6)$ & $1(50)$ & $0(0.0)$ & $0(0.0)$ & $0(0.0)$ \\
\hline Not parallel & $27(96.4)$ & $1(50)$ & $4(100)$ & $1(100)$ & $1(100)$ \\
\hline \multicolumn{6}{|l|}{$p=0.00$} \\
\hline \multicolumn{6}{|l|}{ Shape } \\
\hline Irregular & $28(100)$ & $1(50)$ & $3(75.0)$ & $1(100)$ & $1(100)$ \\
\hline Oval/round & $0(0.0)$ & $1(50)$ & $1(25.0)$ & $0(0.0)$ & $0(0.0)$ \\
\hline \multicolumn{6}{|l|}{$p=0.00$} \\
\hline \multicolumn{6}{|l|}{ Margin } \\
\hline Circumscribed & $5(17.9)$ & $1(50)$ & $2(50)$ & $0(0.0)$ & $0(0.0)$ \\
\hline Non-circumscribed & $23(82.1)$ & $1(50)$ & $2(50)$ & $1(100)$ & $1(100)$ \\
\hline \multicolumn{6}{|l|}{$p=0.013$} \\
\hline \multicolumn{6}{|l|}{ Calcification } \\
\hline Present & $7(25.0)$ & $0(0.0)$ & $0(0.0)$ & $0(0.0)$ & $0(0.0)$ \\
\hline Absent & $21(75.0)$ & $2(100)$ & $4(100)$ & $1(100)$ & $1(100)$ \\
\hline \multicolumn{6}{|l|}{$p=0.014$} \\
\hline \multicolumn{6}{|l|}{ Posterior features } \\
\hline Shadowing enhancement & $20(71.4)$ & $0(0.0)$ & $0(0.0)$ & $0(0.0)$ & $0(0.0)$ \\
\hline Mixt nonenhancement & $4(14.3)$ & $0(0.0)$ & $1(25.0)$ & $0(0.0)$ & $0(0.0)$ \\
\hline \multirow[t]{2}{*}{$p=0.00$} & $3(10.7)$ & $2(100.0)$ & $3(75.0)$ & $1(100.0)$ & $0(0.0)$ \\
\hline & $1(3.6)$ & $0(0.0)$ & $0(0.0)$ & $0(0.0)$ & $1(100.0)$ \\
\hline Mean SWV (m/s) & $6.93 \pm 1.84$ & $3.50 \pm 0.70$ & $5.30 \pm 3.31$ & 7.4 & 4.7 \\
\hline Total & $28(77.7)$ & $2(5.5)$ & $4(11.11)$ & $1(2.77)$ & $11(2.77)$ \\
\hline
\end{tabular}

SD - standard deviation, $p<0.05$, IDC - invasive ductal carcinoma, DCIS - ductal carcinoma in situ

The mean age was $52.9 \pm 13.6$ years in patients with malign lesions. The mean size of benign lesions was $26 \pm 11.23 \mathrm{~mm}$. Subtypes, morphological features, and SWV values of the benign lesions are shown in Table 2.

Seven of the malignant lesions were in subjects under 40 years old and 29 were over 40 years old. The rate of malignancy increased with patients' age $(p<0.05)$. No statistically significant difference was found in sizes of malignant and benign lesions. Whereas the majority of malignant lesions were invasive ductal carcinomas (IDC), the most common histopathological diagnosis of benign lesions was fibroadenoma (FA).
When comparing the morphological features of benign and malignant lesions, the internal echoes of the malign masses were markedly hypoechoic (25.0\%) and hypoechoic (69.4\%). In particular, the sonographic presentation of complex echoes was more common in benign lesions $(37.7 \%)$ than in malign lesions. However, isohyperechogenicity was observed only in benign lesions. The shape of the breast lesions was more often irregular in the malign lesions (91.7\%) and was less frequently oval or round. Regarding the tumour margin, malign lesions were more likely non-circumscribed (77.8\%). For the posterior features, benign lesions comprised $37.0 \%$ and $34.4 \%$ 
Table 3. Comparison of benign and malignant lesions' B-mode US morphological characteristics and mean shear wave velocity (SWV) values

\begin{tabular}{|c|c|c|}
\hline \multirow[t]{2}{*}{ US features } & \multicolumn{2}{|c|}{ Histopathology (HPE) } \\
\hline & $\begin{array}{l}\text { Benign } \\
n(\%)\end{array}$ & $\begin{array}{c}\text { Malignant } \\
n(\%)\end{array}$ \\
\hline \multicolumn{3}{|l|}{ Echo pattern } \\
\hline Markedly hypoechoic & $1(0.6)$ & $9(25.0)$ \\
\hline Hypoechoic & $90(58.4)$ & $25(69.4)$ \\
\hline Isoechoic & $2(1.3)$ & $0(0.0)$ \\
\hline Hyperechoic & $3(1.9)$ & $0(0.0)$ \\
\hline Complex & $58(37.7)$ & $2(5.6)$ \\
\hline \multicolumn{3}{|l|}{$p=0.00$} \\
\hline \multicolumn{3}{|l|}{ Orientation } \\
\hline Parallel & $56(36.4)$ & $2(5.6)$ \\
\hline Not parallel & $98(63.6)$ & $34(94.4)$ \\
\hline \multicolumn{3}{|l|}{$p=0.00$} \\
\hline \multicolumn{3}{|l|}{ Shape } \\
\hline Irregular & $88(57.1)$ & $33(91.7)$ \\
\hline Oval/round & $66(42.9)$ & $3(8.3)$ \\
\hline \multicolumn{3}{|l|}{$p=0.00$} \\
\hline \multicolumn{3}{|l|}{ Margin } \\
\hline Circumscribed & $69(44.8)$ & $8(22.2)$ \\
\hline Non-circumscribed & $85(55.2)$ & $28(77.8)$ \\
\hline \multicolumn{3}{|l|}{$p=0.013$} \\
\hline \multicolumn{3}{|l|}{ Calcification } \\
\hline Present & $5(3.2)$ & $7(19.4)$ \\
\hline Absent & $149(96.8)$ & $29(80.6)$ \\
\hline \multicolumn{3}{|l|}{$p=0.014$} \\
\hline \multicolumn{3}{|l|}{ Posterior features } \\
\hline Shadowing & $11(7.1)$ & $20(55.6)$ \\
\hline Enhancement & $57(37.0)$ & $5(13.9)$ \\
\hline Mixt & $53(34.4)$ & $9(25.0)$ \\
\hline Nonenhancement & $33(21.4)$ & $2(5.6)$ \\
\hline \multicolumn{3}{|l|}{$p=0.00$} \\
\hline $\begin{array}{l}\text { Mean SWV }(\mathrm{m} / \mathrm{s}) \pm S D \\
p=0.00\end{array}$ & $3.82 \pm 1.59$ & $6.51 \pm 2.12$ \\
\hline Total & $154(81.1)$ & $36(18.9)$ \\
\hline
\end{tabular}

the posterior acoustic enhancement-mix enhancement; however, malignant lesions showed posterior shadowing feature of $55.6 \%(p<0.05)$.

When comparing values of SWV, the benign breast masses showed $3.82 \pm 1.59 \mathrm{~m} / \mathrm{s}$ at SWE and the malign breast masses $6.51 \pm 2.12 \mathrm{~m} / \mathrm{s}(p=0.00)$. The comparison of benign and malign lesions' B-mode US morphological characteristics and mean SWV values are summarised in Table 3.
Table 4. BI-RADS-histopathology and shear wave velocity (SWV) comparison

\begin{tabular}{|l|c|c|c|c|}
\hline \multirow{2}{*}{ BIRADS } & \multicolumn{2}{|c|}{ Histopathology (HPE) } & \multirow{2}{*}{$\begin{array}{c}\text { Mean SWV } \\
(\mathrm{m} / \mathrm{s}) \pm \text { SD }\end{array}$} & \\
\cline { 2 - 3 } & $\begin{array}{c}\text { Benign } \\
n(\%)\end{array}$ & $\begin{array}{c}\text { Malignant } \\
n(\%)\end{array}$ & & \\
\hline 3 & $62(96.8)$ & $2(3.1)$ & $3.61 \pm 1.18$ & 64 \\
\hline 4 & $86(82.7)$ & $18(17.3)$ & $4.67 \pm 1.83$ & 104 \\
\hline 5 & $6(27.3)$ & $16(72.7)$ & $6.27 \pm 2.57$ & 22 \\
\hline Total & $154(81.1)$ & $36(18.9)$ & $4.50 \pm 1.92$ & 190 \\
\hline
\end{tabular}

BI-RADS - breast imaging reporting and data system, $p<0.05$

Table 5. Shear wave velocity (SWV) values of malignant and benign lesions in VTQ

\begin{tabular}{|l|c|c|c|c|}
\multirow{2}{*}{$\begin{array}{l}\text { Histopathology } \\
\text { (HPE) }\end{array}$} & \multicolumn{2}{|c|}{ SWV values } & \multirow{2}{*}{$\begin{array}{c}\text { Total } \\
n(\%)\end{array}$} & $p$ \\
\cline { 2 - 4 } & $\begin{array}{c}\text { Less } \\
\text { than } 3 \mathrm{~m} / \mathrm{s} \\
n(\%)\end{array}$ & $\begin{array}{c}\text { More } \\
\text { than } 3 \mathrm{~m} / \mathrm{s} \\
n(\%)\end{array}$ & & \\
\cline { 1 - 4 } malignant & $3(8.3)$ & $33(91.6)$ & $36(18.9)$ & 0.044 \\
\hline benign & $63(40.9)$ & $91(59.1)$ & $154(81.1)$ & \\
\hline total & $66(34)$ & $124(65.2)$ & 190 & \\
\hline
\end{tabular}

$p<0.05$

Based on the analysis of the morphological features of breast lesions, 64 lesions were classified as BI-RADS 3, and 125 lesions were classified as BI-RADS 4-5, the latter group requiring biopsy. Two lesions (3.1\%) in the BI-RADS 3 category resulted in malignant histopathology. Histopathological results were adenocarcinoma and mucinous cancer. While SWV values were $5 \mathrm{~m} / \mathrm{s}$ and $3 \mathrm{~m} / \mathrm{s}$, respectively, these lesions' morphological features were circumscribed margin, parallel orientation, oval shape, and multilobulation (Table 4). While SWV values provide clues for adenocarcinoma, the SWV value mucinous cancer was similar to that of benign lesions.

Considering the cut-off value of $3 \mathrm{~m} / \mathrm{s}$ in the differentiation of the malignant and benign character lesions, the SWV value was $>3 \mathrm{~m} / \mathrm{s}$ in 33 and $<3 \mathrm{~m} / \mathrm{s}$ in three of the malignant lesions, whereas SWV was $>3 \mathrm{~m} / \mathrm{s}$ in 91 and $<3 \mathrm{~m} / \mathrm{s}$ in 63 of the benign lesions (Table 5). Discordant elasticity findings were found in $59.1 \%$ of the benign and $8.3 \%$ of the malignant lesions. False positivity was statistically significantly higher than false negativity $(p<0.05)$. Among the benign lesions, SWV values were as high as the SWV values of malignant lesions, especially in the lesions such as granulomatous mastitis, sclerosing adenosis, chronic inflammation, fat necrosis, fibrotic breast tissue, and scar tissue. Two patients with fat necrosis had a trauma history, while six had a history of breast reduction, and one had a postoperatively formed lesion. In particular, lesions with fat necrosis were the lesions with the highest (mean SWV: $5.4 \pm 2.06 \mathrm{~m} / \mathrm{s}$ ) SWV (Figure 1). Patients with scar tissue were those who had undergone partial mastec- 

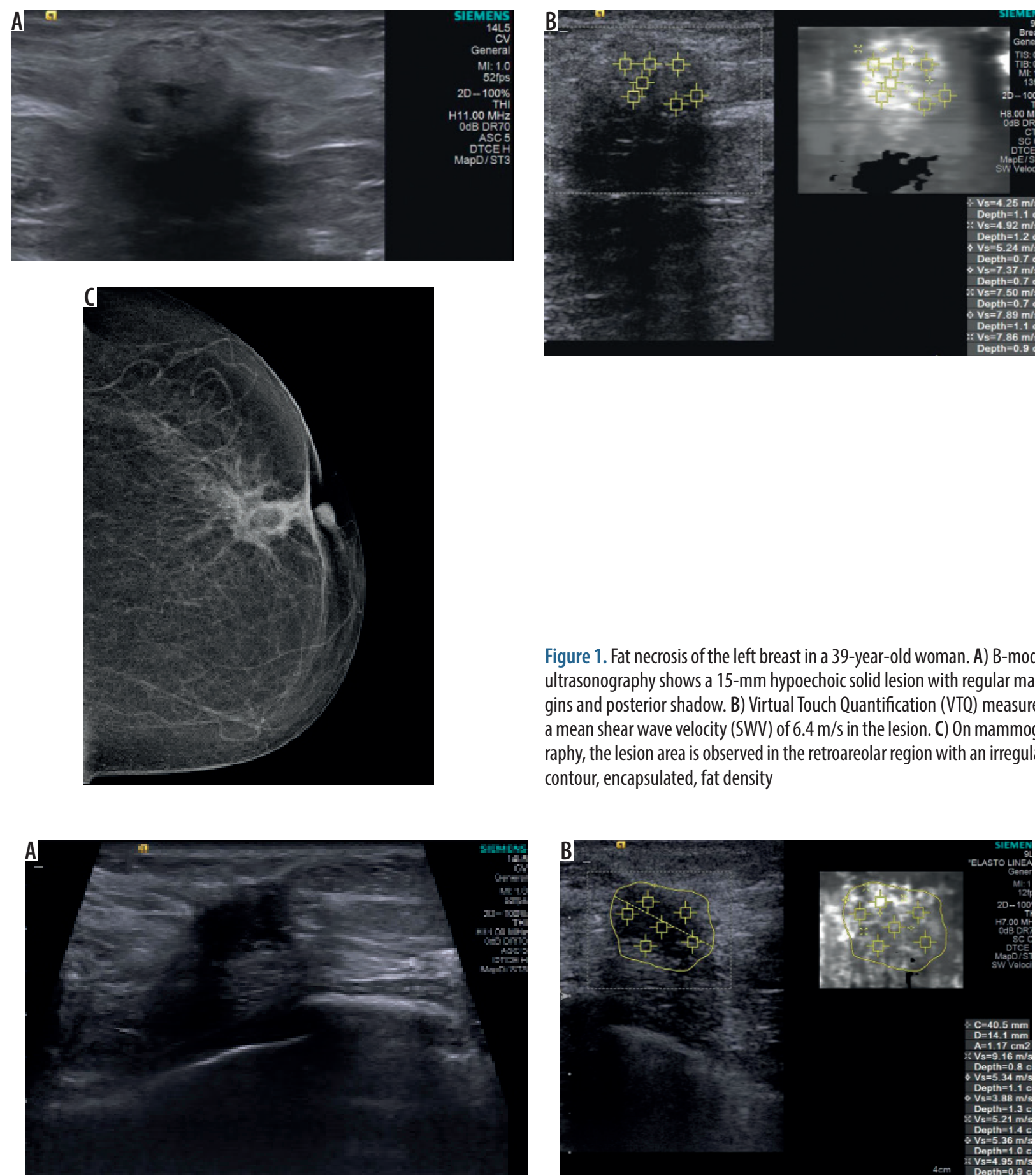

Figure 2. A 55-year-old woman in postoperative period, scar tissue of the left breast. A) B-mode ultrasonography shows a 22-mm hypoechoic solid lesion with irregular margins. B)Virtual Touch Quantification (VTQ) measures a mean shear wave velocity (SWV) of $5.6 \mathrm{~m} / \mathrm{s}$ in the lesion

tomy following the diagnosis of breast cancer, and they were the cases identified at postoperative follow-up (Figure 2). All malignant lesions diagnosed with IDC had irregular spiculated contours on B-mode US, and the mean SWV value of these tumours was high (mean SWV: 6.94 $\pm 1.84 \mathrm{~m} / \mathrm{s}$ ). While the lesions diagnosed with mucinous cancer were regular and multilobulated, one of them in an elderly patient included calcification, with a high SWV (mean SWV: $4.1 \mathrm{~m} / \mathrm{s}$ ) (Figure 3). Lesions of the patients with granulomatous mastitis showed both low and high

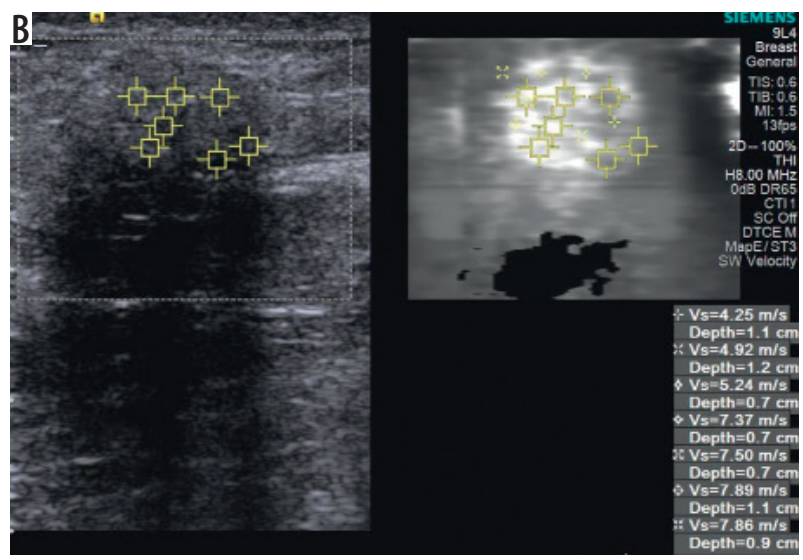

Figure 1. Fat necrosis of the left breast in a 39-year-old woman. A) B-mode ultrasonography shows a $15-\mathrm{mm}$ hypoechoic solid lesion with regular margins and posterior shadow. B) Virtual Touch Quantification (VTQ) measures a mean shear wave velocity (SWV) of $6.4 \mathrm{~m} / \mathrm{s}$ in the lesion. C) On mammography, the lesion area is observed in the retroareolar region with an irregular contour, encapsulated, fat density elasticity in SWV. However, the mean SWV was high in the majority of the patients with granulomatous mastitis (mean SWV: $4 \pm 1.21 \mathrm{~m} / \mathrm{s}$ ) (Figure 4). Ductal carcinoma in situ (DCIS) was monitored as periductal thickening and dense ductal content on B-mode US with a mean SWV value of $3.4 \mathrm{~m} / \mathrm{s}$. The mean SWV of the small lesions $(<2 \mathrm{~cm})$ was $4.23 \pm 1.84 \mathrm{~cm} / \mathrm{s}$, while the mean SWV of the large lesions $(\geq 2 \mathrm{~cm})$ was $4.87 \pm 1.99 \mathrm{~cm} / \mathrm{s}(p=0.02)$.

The sensitivity, specificity, and accuracy of the BIRADS classification system were $94 \%, 40 \%$, and $50.5 \%$ 

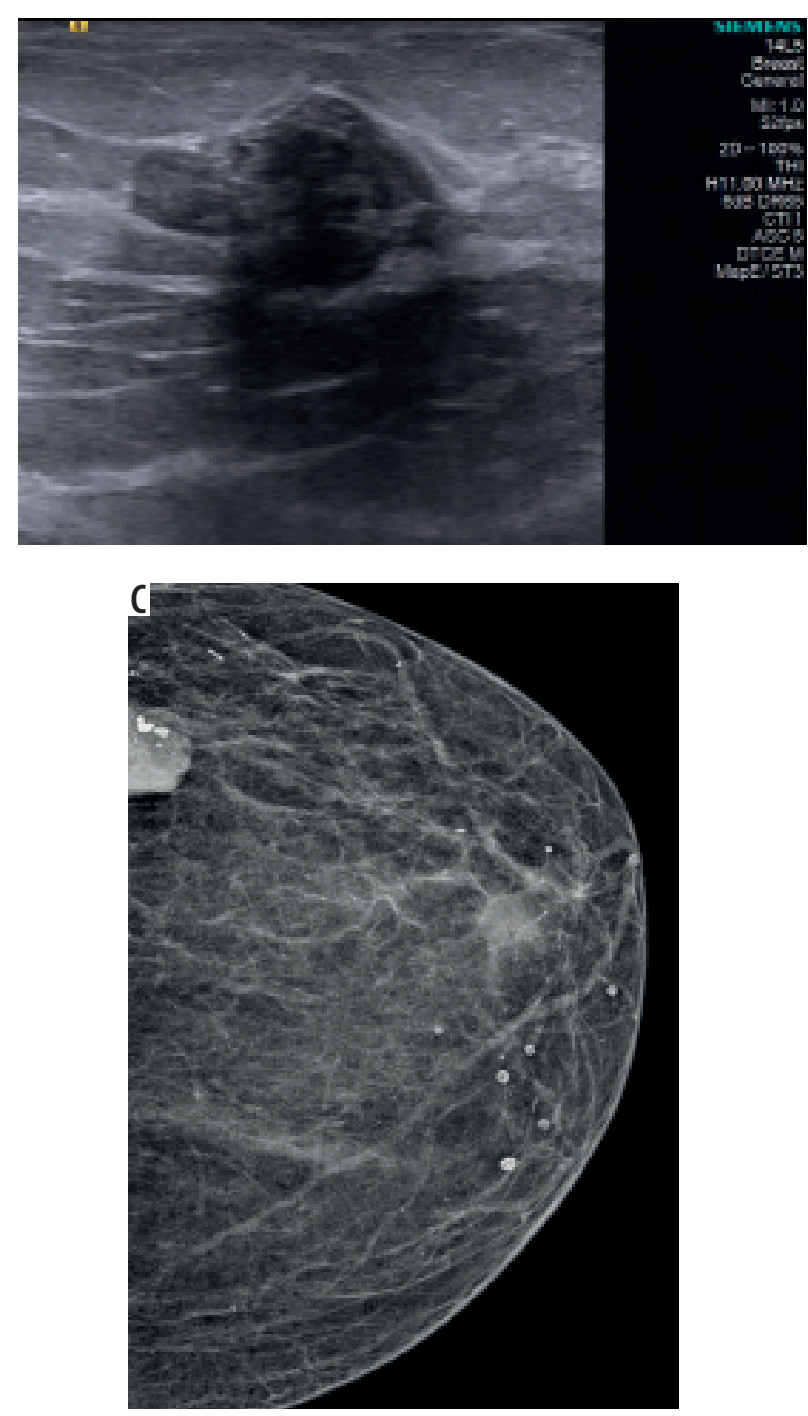

for the greyscale ultrasound and 91\%, 41\%, and 50.5\% for SWV values in ARFI US, respectively; the results were similar for both evaluations. Positive predictive value (PPV) and negative predictive value (NPD) were found to be similar for SWV and BI-RADS categorisation (for SWV - PPD: 26.6\%, NPD: 95.4\% and for BI-RADS PPD: 29\%, NPD: 96\%).

\section{Discussion}

In the present study, we ascertained which breast lesions showed false positivity (59.1\%) and false negativity (8.3\%) with VTQ measurement on ARFI US in patients evaluated and biopsied in our clinic. The lesions with false positivity were more common than the lesions showing false negativity.

It has been reported that, in addition to conventional sonography, breast elastography provides quantitative data about the elasticity of the lesions, giving more objective information for lesion characterisation [10-12]. This technique has become a method used in addition to the diagnostic US in the last five years [5]. Elastography is

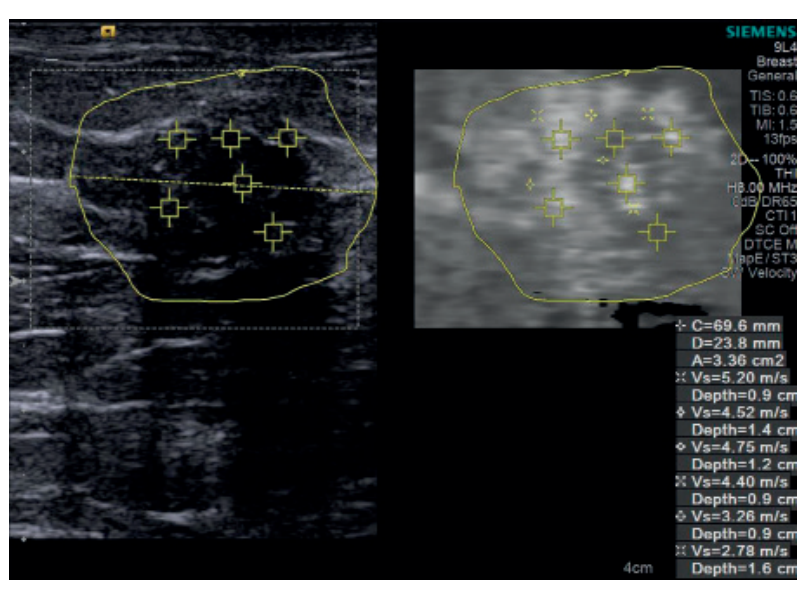

Figure 3. A) A 77-year-old old woman; irregular lobulated contoured, hypoechoic, solid, mucinous cancer on B-mode ultrasonography image. B) Virtual Touch Quantification (VTQ) measures a mean shear wave velocity (SWV): $4.1 \mathrm{~m} / \mathrm{s}$ in the lesion. C) Deep localised, lobulated contoured, dense, mucinous carcinoma containing calcifications in the left quadrant of the left breast on craniocaudal mammography

highly helpful and precise in the evaluation of the lesions in various organs including the breasts $[13,14]$. The use of quantitative elastography with SWV increases diagnostic accuracy in equivalent cases. SWV differs with an elasticity between benign and malignant lesions; while benign lesions have an elasticity similar to the surrounding tissues, malignant lesions are harder than the adjacent tissue [15]. Elasticity characteristics may overlap in benign and malignant lesions, depending on histopathological features in breast tumours [9]. Some benign breast lesions may show a high SWV value and mimic malignant lesions [11]. Because breast parenchyma decreases elasticity waves, it is known that a deeply localised lesion may give elasticity scores incompatible with histopathological outcomes [12]. Among the factors affecting SWV values, a study has shown that superficial lesions have more accurate elasticity outcomes than the deep lesions [16]. In addition, elasticity scores are associated with the compression applied by the practitioner [16]. Breast tumours usually become weakly deformed compared to benign lesions. On the other hand, some benign lesions such as fibrous FAs and scar tissues may also become weakly deformed [17]. 

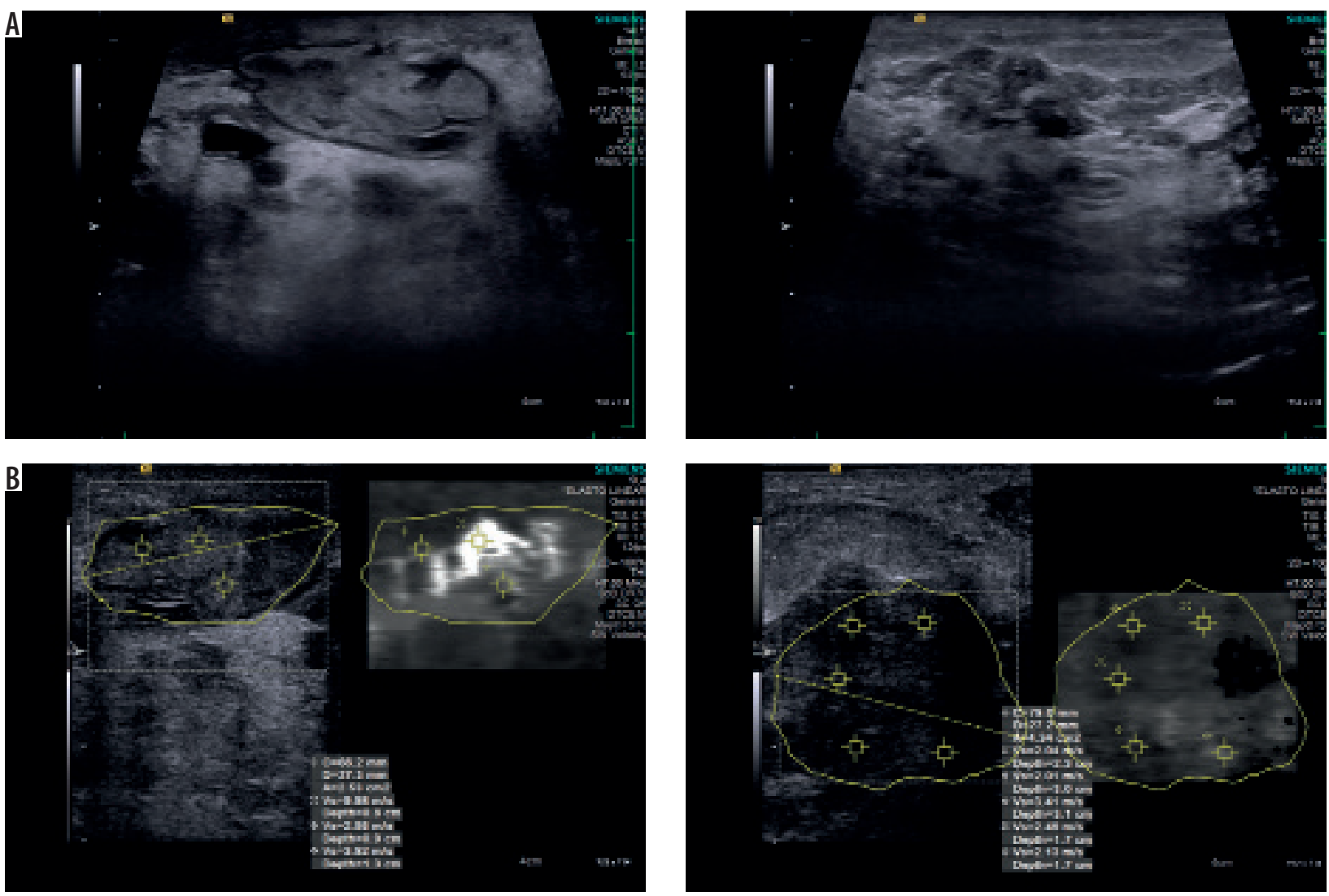

Figure 4. A) A 33-year-old woman; granulomatous mastitis containing areas in the form of finger-like projections and showing sporadic fluid loculations on B-mode ultrasonography. B) Mean shear wave velocity (SWV) values from 2 different areas in shear wave elastography SWE) (2.4 m/s at the right and $5.5 \mathrm{~m} / \mathrm{s}$ at the left)

In our study, among the benign lesions in our patient group, scar tissue (mean SWV: $4.9 \pm 1.40 \mathrm{~m} / \mathrm{s}$ ) and some FAs showed high SWV values, consistent with the literature. Elastography is not an appropriate modality to evaluate breasts postoperatively because of the high SWV values of scar tissues [17]. The radiological evaluation of the scar tissue should be made carefully. Müller et al., in a study conducted for the detection of cancer recurrence in 84 patients, found seven local recurrences [18]. It is also known that the morphological features of scar tissue can sometimes be similar to malignancy. This can sometimes lead to unnecessary biopsy.

FAs are the most commonly encountered breast masses and are the reason for many unnecessarily performed biopsies. SWE is expected to prevent unnecessary biopsies for FAs [17]. Despite many FAs showing a soft character, some of them are stiff and may exhibit false positivity for malignancy [11]. The cause of the rigidity in FAs has been interpreted in the literature as due to hyaline degeneration [17]. In our study, in some FA lesions, suspicious findings related to elastography may be due to hyaline degeneration and calcification. Sixty-one (32.1\%) lesions were diagnosed with FA in our study group. Forty-three (70.5\%) FAs had SWV values over $3 \mathrm{~m} / \mathrm{s}$. Of these two (3.3\%) had calcification and 41 (67.21\%) had hyaline degeneration. In another study, El Sedawy et al. demonstrated that the most important parameter to determine the hardness de- gree of FAs was lesion size [17]. In the literature, as in our study, the mean SWV value increased with growing FA size to $(p=0.02)$. Again, in the same study, the elasticity of FAs were not correlated with age. In our study, we found the mean SWV value of FA to be $3.7 \pm 1.13 \mathrm{~m} / \mathrm{s}$, independently of age $(p=0.84)$.

Fat necrosis is among the lesions that may be hard in SWE $[19,20]$. In our patient group, fat necrosis lesions were very hard with low elasticity and with very high SWV values $(5.4 \pm 2.06 \mathrm{~m} / \mathrm{s})$. We believe that patient history, B-mode US, and mammography are more efficient in making the decision for biopsy in fat necrosis lesions. Thus, unnecessary biopsies performed in fat necrosis lesions that are palpable, hard, and mimic malignancy clinically and elastographically can be avoided.

Idiopathic granulomatous mastitis (IGM), inflammatory breast cancer (IMC), infectious mastitis, foreign body injection granulomas, mammary duct ectasia, and diabetic fibrous mastopathy are breast diseases with similar features, and diagnosis is often challenging [21]. These diseases clinically mimic breast cancer [22]. In general, they manifest as a unilateral hard mass accompanied by thickening and erythema of the skin [22]. Multiple and irregular hypoechoic masses and collections on the US that contain skin formation in the skin and finger-like tubular connections suggest IGM instead of carcinoma in patients with a history of breastfeeding [23]. 
In our patient group, the high SWV values (mean SWV: $4 \pm 1.21 \mathrm{~m} / \mathrm{s}$, min: $2.2 \mathrm{~m} / \mathrm{s}$, max: $6.3 \mathrm{~m} / \mathrm{s}$ ) in $19(9.9 \%)$ IGM cases may be explained by increased collagen-rich fibrous tissue and granulomas. In a study on this issue, the mean SWV was found to be $3.19 \mathrm{~m} / \mathrm{s}$ (min: $2.49 \mathrm{~m} / \mathrm{s}$, $\max$ : $5.82 \mathrm{~m} / \mathrm{s}$ ) for IGM [24].

On the other hand, early-stage breast carcinomas, malignant masses with necrosis, and mucinous cancers have soft characteristics and may lead to false negative outcomes [25]. In addition, some invasive cancers may show soft elasticity, causing a false negative outcome [12]. In our study, one patient with IDC and one patient with adenocarcinoma showed low elasticity. Mucinous carcinomas, some inflammatory breast cancers, and carcinomas $<5 \mathrm{~mm}$ may become highly deformed with pseudobenign characteristics [17]. In our study group, there were two patients with mucinous carcinomas, which are known to show false negativity from the literature. The mean SWV value of one patient was low, consistent with the literature $(3 \mathrm{~m} / \mathrm{s})$, while the other patient had a high mean SWV value $(4 \mathrm{~m} / \mathrm{s})$, which was incompatible with the literature. This was attributed to the lesion containing calcification. In addition, it was found in a study that mucinous cancers did not show different elasticity compared to the other malignant tumour types [26]. Although SWE provides quantitative data reflecting internal features of the target mass, some SWE outcomes may be in contrast to the real histopathological diagnosis. Furthermore, studies have shown that nearly $10.3 \%$ to $15.1 \%$ of benign or malignant masses show SWE features incompatible with the histopathological diagnosis, leading to false positive or false negative SWE outcomes $[10,26]$. In our study, this rate was $49.4 \%$. In the present study, the mean SWV values were significantly higher in the malignant lesions compared to the benign lesions, with sensitivity and NPD values of $91.6 \%$ and $95.4 \%$, respectively. This value is high and indicates that SWV measurement in the VTQ method with ARFI US is highly sensitive in the detection of malignant lesions. In our patient group, the rate of SWE scores that were incompatible with the histopathological outcomes was $49.4 \%$, with specificity and PPD values of $40.9 \%$ and $26.6 \%$, respectively. These findings were attributed to relatively high rates of mastitis, scar tissue, fat necrosis, fibrotic breast tissue, and sclerosing adenosis lesions that showed false positivity. In one of two different studies in the literature, SWE scores incompatible with the histopathological outcomes were more common in the malignant lesions than in the benign lesions, while in the other study benign lesions showed more incompatible SWE values than the malignant ones [12,26]. In our study also SWE scores incompatible with the histopathological outcomes were more common in the benign lesions (false positivity in the benign lesions: $59.1 \%$, false negativity in the malignant lesions: $8.3 \%, p<0.05$ ).

\section{Conclusions}

Besides the known benefits of elastography, we believe that, knowing lesions showing false positivity and negativity due to different elasticity features, evaluation of elastographic outcomes together with B-mode US will be helpful in preventing delayed diagnoses and unnecessary biopsies.

This study has some limitations. We did not consider increased SWV measurements caused by lesion depth, and compression by the practitioner when SWV values of the lesions were measured. Small malignant lesions are softer than invasive carcinomas and may give false negative SWE values [11]. Choi et al. showed that as the lesion size decreases, and farther from the skin false negative results increase in malignant breast lesions; furthermore, when the lesion was close to the skin, they stated that false positivity increased [27]. However, since in our study the mean size of malignant lesions was high, we did not observe the false negative SWV values that may be seen in small malignant lesions. Furthermore, we did not calculate the distance of the lesions from the skin, so this may have increased the false positive results of lesions close to the skin in our patient group. In addition, the number of lesions that are known to be false negative from the literature was low in our patient group. Because the study was conducted retrospectively, the lesions showing false positivity in SWE might be selected in the patient group. This might cause low NPD and specificity.

\section{Conflict of interest}

The authors report no conflict of interest.

\section{References}

1. Jemal A, Bray F, Center MM, et al. Global cancer statistics. CA Cancer J Clin 2011; 61: 69-90.

2. Itoh A, Ueno E, Tohno E, et al. Breast disease: clinical application of US elastography for diagnosis. Radiology 2006; 239: 341-350.

3. Wang ZL, Li N, Li M, et al. Non-mass-like lesions on breast ultrasound: classification and correlation with histology. Radiol Med 2015; 120: 905-910
4. Goddi A, Bonardi M, Alessi S. Breast elastography: a literature review. J Ultrasound 2012; 15: 192-198.

5. Balleyguier C, Canale S, Ben Hassen W, et al. Breast elasticity: principles, technique, results: an update and overview of commercially available software. Eur J Radiol 2013; 82: 427-434.

6. Kapetas P, Woitek R, Clauser P, et al. A simple ultrasound based classification algorithm allows differentiation of benign from ma- 
lignant breast lesions by using only quantitative parameters. Mol Imaging Biol 2018; 9: 1-8.

7. Bai M, Du L, Gu J, et al. Virtual touch tissue quantification using acoustic radiation force impulse technology: initial clinical experience with solid breast masses. J Ultrasound Med 2012; 31: 289-294.

8. Taşkın F. Mamografi ve Ultrasonografi Tekniğinde Gelişmeler: Tomosentez, Kontrastlı Mamografi ve Elastografi. Turkiye Klinikleri J Radiol-Special Topics 2017; 10: 222-230.

9. American College of Radiology. ACR BI-RADS-US. In: ACR Breast Imaging Reporting and Data System. American College of Radiology, Reston 2013.

10. Chang JM, Moon WK, Cho N, et al. Clinical application of shear wave elastography (SWE) in the diagnosis of benign and malignant breast diseases. Breast Cancer Res Treat 2011; 129: 89-97.

11. Yoon JH, Jung HK, Lee JT, et al. Shear-wave elastography in the diagnosis of solid breast masses: what leads to false-negative or false-positive results? Eur Radiol 2013; 23: 2432-2440.

12. Lyshchik A, Higashi T, Asato R, et al. Cervical lymph node metastases: diagnosis at sonoelastography-initial experience. Radiology 2007; 243: 258-267.

13. Bercoff J, Tanter M, Fink M. Supersonic shear imaging: a new technique for soft tissue elasticity mapping. IEEE Trans Ultrason Ferroelectr Freq Control 2004; 51: 396-409.

14. Hiltawsky KM, Kruger M, Starke C, et al. Freehand ultrasound elastography of breast lesions: clinical results. Ultrasound Med Biol 2001; 27: 1461-1469.

15. Ciurea AI, Bolboaca SD, Ciortea CA, et al. The influence of technical factors on sonoelastographic assessment of solid breast nodules. Ultraschall Med 2011; 32: 27-34.

16. Balleyguier C, Ciolovan L, Ammari S, et al. Breast elastography: the technical process and its applications. Diagn Interv Imaging 2013; 94: 503-513.
17. Elseedawy M, Whelehan P, Vinnicombe S, et al. Factors influencing the stiffness of fibroadenomas at shear wave elastography. Clin Radiol 2016; 71: 92-95.

18. Faruk T, Islam MK, Arefin S, et al. The journey of elastography: background, current status, and future possibilities in breast cancer diagnosis. Clin Breast Cancer 2015; 15: 313-324.

19. Pluguez-Turull CW, Nanyes JE, Quintero CJ, et al. Idiopathic granulomatous mastitis: manifestations at multimodality imaging and pitfalls. Radiographics 2018; 38: 330-356.

20. Memis A, Bilgen I, Ustun EE, et al. Granulomatous mastitis: imaging findings. Clin Radiol 2002; 57: 1001-1006.

21. Yildiz S, Aralasmak A, Kadioglu H, et al. Radiologic findings of idiopathic granulomatous mastitis. Med Ultrason 2015; 17: 39-44.

22. Teke M, Teke F, Alan B, et al. Differential diagnosis of idiopathic granulomatous mastitis and breast cancer using acoustic radiation force impulse imaging. J Med Ultrason 2017; 44: 109-115.

23. Raza S, Odulate A, Ong EM, et al. Using real-time tissue elastography for breast lesion evaluation: our initial experience. J Ultrasound Med 2010; 29: 551-563.

24. Evans A, Sim YT, Thomson K, et al. Shear wave elastography of breast cancer: Sensitivity according to histological type in a large cohort. Breast 2016; 26: 115-118.

25. Gweon HM, Youk JH, Son EJ, et al. Visually assessed colour overlay features in shear-wave elastography for breast masses: quantification and diagnostic performance. Eur Radiol 2013; 23: 653-658.

26. Yoon JH, Kim MJ, Kim EK, et al. Discordant elastography images of breast lesions: how various factors lead to discordant findings. Ultraschall Med 2012; 33: 145-150.

27. Choi HY, Seo M, Sohn YM, et al. Shear wave elastography for the diagnosis of small $(\leq 2 \mathrm{~cm})$ breast lesions: added value and factors associated with false results. Br J Radiol 2019; 92: 20180341. 